\title{
EXCHANGING VIEWS ON HTA
}

This issue of the International Journal of Technology Assessment in Health Care (IJTAHC) brings to the readers a lively discussion on the possibility of benchmarking health technology assessment (HTA) organizations. Michael Drummond and colleagues present a paper discussing "the conceptual and methodological challenges associated with benchmarking" (1). They propose a set of criteria for comparing the quality of organizations that produce assessments on health technologies. Aiming at explicit and transparent comparisons, Drummond et al. also highlight the possible problems in their approach, and present their paper as a starting point for discussion.

To facilitate such discussion, I invited three seasoned HTA experts to comment on the paper. Their comments accompany the original suggestion in this issue. Among our readers, there are surely even more viewpoints on this matter. Enjoy the debate, and feel free to formulate your own views: brief letters (up to 150 words) are welcomed; please submit these through the Journal's Web site at http://mc.manuscriptcentral.com/ thc.

Writing letters and waiting for these to be published may seem old-fashioned in this age of blogs and twittering. But the publication process can and should be used to formulating thoughts clearly. Editing is done for user benefit; when authors chisel away unnecessary bits, solidify arguments, and organize them logically, they save readers' time. A pertinent letter and a considered reply are food for thought, and fruitful exchange of views through letters to this Journal signals a living HTA community.

The role of scientific journals is on the move, as we communicate more online. The printed article has its limits, even if we accept more than many journals, up to 4000 words. Supplements on the Web site can bring extra information to the reader. Systematic reviews are the real winners here: full search strategies and other methodological details are made available in addition to the concise text. Asking for more information from authors is also easier than ever, so we should not overwhelm the reader with supplements - it's prudent to edit these too.

When IJTAHC was established, it was difficult to get hold of assessments published in other countries. For years, national HTA offices actually exchanged reports on paper. Now pdf versions of assessments are accessible over the world before the text is printed. This journal has continued the tradition of publishing summaries of HTAs even when the original versions are available; one reason is the language hurdle. Assessments in Mediterranean or Scandinavian languages are not fully readable to most colleagues in other countries.

At this halfway point of my 5-year contract as Editor-inChief, I now have sufficient material to shift from technical renewal to content issues. Here, I need your opinion, dear reader. Do you think it's useful to publish summaries of HTAs already available on the Web? How detailed should our methodology papers be? How much space should we earmark for systematic reviews, and how much supplementary material do you actually wish to see on the Web site? Would you like to see theme sections as part of an ordinary issue, or do you prefer separate theme issues? Should we treat papers from countries where HTA is emerging with less strict criteria than from lands with decades of HTA activity?

A brief survey on developing IJTAHC has been set up on the Web site of the organization behind this journal, Health Technology Assessment International (HTAi). Please think what you want from this journal and answer the questions at www.htai.org. You can also give ideas for theme issues or suggest other improvements. And yes, we are going to change the reference system to Vancouver in 2013. The editorial team looks forward to hearing from our audience.

Marjukka Mäkelä, MD, PhD, MSc

Editor-in-Chief, International Journal of Technology Assessment in Health Care

Director of FINOHTA (Finnish Office for Health Technology Assessment)

at THL (National Institute of Health and Welfare)

IJTAHC Editorial Office

Helsinki, Finland

IJTAHC@thl.fi

\section{CONFLIC OF INTEREST}

The author's institute receives a grant from the European Commission.

\section{REFERENCE}

1. Drummond D, Neumann P, Jönsson B, et al. Can we reliably benchmark health technology assessment organizations? Int J Technol Assess Health Care. 2012;28:159-165. 